\title{
Determinants and consequences of smoke-free homes: findings from the International Tobacco Control (ITC) Four Country Survey
}

\author{
R Borland, H-H Yong, K M Cummings, A Hyland, S Anderson, G T Fong
}

Tobacco Control 2006;15(Suppl III):iii42-iii50. doi: 10.1136/tc.2005.012492

See end of article for authors' affiliations

\section{Correspondence to:} Ron Borland, PhD, Cancer Control Research Institute, The Cancer Council

Victoria, 1 Rathdowne

Street, Carlton, VIC 3053,

Australia; Ron.Borland@

cancervic.org.au

Received 13 May 2005

Accepted 29 November

2005

\begin{abstract}
Objective: To report on prevalence, trends and determinants of smoke-free home policies in smokers' homes in different countries and to estimate the effects of these policies on smoking cessation. Design: Two waves of the International Tobacco Control (ITC) Four Country Survey (ITC-4), a cohort survey of smokers conducted by telephone. Wave 1 was conducted in October/December 2002 with broadly representative samples of over 2000 adult ( $\geqslant 18$ years) cigarette smokers in each of the following four countries: Canada, the United States, the United Kingdom, and Australia, 75\% of whom were followed up at Wave 2 on average seven months later.

Key measures: Levels of smoking restrictions in homes (both waves).

Results: Australian smokers were most likely to live in smoke-free homes and UK smokers least likely (34\% $v 15 \%$ at Wave 1). Levels of smoke-free homes increased between waves. Logistic regressions indicated that the main independent predictors of smokers reporting smoke-free homes or implementation of a smoke-free policy between waves included household factors such as having a child, particularly a young child, and having other non-smoking adults in the household. Positive attitudes to smoke-free public places and/or reported presence of smoke-free public places were independent predictors of having or implementing smoke-free homes, supporting a social diffusion model for smoking restrictions. Intentions to quit at Wave 1 and quitting activity between survey waves were associated with implementing bans between Waves 1 and 2. Presence of bans at Wave 1 was associated with significantly greater proportions of quit attempts, and success among those who tried at Wave 2. There was no significant interaction between the predictive models and country.

Conclusions: Smoke-free public places seem to stimulate adoption of smoke-free homes, a strategy associated with both increased frequency of quit attempts, and of the success of those attempts.
\end{abstract}

T he adverse effects of exposure to tobacco smoke pollution (TSP) have led to policies prohibiting smoking in a range of public settings including workplaces ${ }^{12}$ and recreational facilities. ${ }^{3}$ In private homes, the enclosed environment where people generally spend most time, there is a reliance on householders adopting rules voluntarily.

There is evidence from a small number of countries that householders, including many smokers, are increasingly making their homes smoke-free. ${ }^{4-6}$ Restrictions are more common when there are non-smoking adults in the home and where there are children present, ${ }^{5-10}$ and this can result in reduced TSP exposures in the children. ${ }^{10}{ }^{11}$ Smoke-free homes have also been associated with increased quitting among smokers. ${ }^{12}{ }^{13}$ The Farkas et al ${ }^{12}$ study used retrospective data on quitting over the previous year among respondents to the large Cancer Prevention Study survey in the USA. They found greater quitting and lower cigarette consumption, but were unable to test to see if the effects were of smoke-free leading to quitting or quit attempts leading to smoke-free. Pizacani et al, ${ }^{13}$ in a small prospective study conducted over 21 months, found that being smoke-free at baseline predicted subsequent cessation, but only among those in the preparation stage of change.

The overall aim of this study was to explore patterns of reported smoking bans in the homes of smokers across four countries that are part of the International Tobacco Control (ITC) Four Country Survey (ITC 4: Canada, the USA, the UK, Australia) and estimate the effects of such voluntary policies on smoking cessation. We were interested in exploring possible determinants of imposing restrictions to build our understanding of the factors involved in successfully implementing smoke-free homes. We are particularly interested in the relationship between home bans and bans in the public environment. Opponents of the extension of smoke-free public places to recreational venues have argued that these bans will result in more smoking at home, exposing nonsmoking family members to TSP. This "last refuge" model could, if correct, result in net social costs of bans as there would be more harms from extended home exposures to family members, especially children (who may be more vulnerable to TSP) than benefits from those protected in bars, where all but the staff spend limited time. By contrast, a social diffusion model would suggest that the more restrictions there are, the more likely that householders would be to impose voluntary bans, thus increasing the net benefits of imposing bans in public places. There is some evidence that those subject to bans in workplaces are more likely to have bans in their homes. ${ }^{5}$ As far as we know, there is no evidence on the relationship between home bans and restrictions in other places particularly recreational venues.

Our first aim was to report overall prevalence of smoke-free homes among homes in which smokers live, and to do so by country. Second, we explored factors that are associated with

Abbreviations: CATI, computer assisted telephone interview; $\mathrm{HSI}$ heaviness of smoking index; ITC, International Tobacco Control; ITC-4, International Tobacco Control Four Country Survey; SES, socioeconomic status; TSP, tobacco smoke pollution 
the presence of smoke-free homes or their initiation using prospective data. In particular we wanted to replicate past findings that presence of non-smokers and children were associated with increased bans. Beyond this, we were interested in possible differences by sociodemographic strata, especially measures of socioeconomic status, smoker characteristics, including degree of dependence, reported reasons for smoking, history of and interest in quitting, and any influence of smoke-free public places. Finally, we were interested in the extent to which smoke-free homes contribute to smoking cessation, both as a strategy to facilitate attempts, and as a background condition that might make quitting easier. In particular, we wanted to see whether any facilitatory attempt was restricted to those with an immediate interest in quitting.

\section{METHOD}

This study reports data from two waves of the ITC-4 Survey, to prospectively examine predictors of implementation of bans and of the consequences of bans on quitting activity in smokers. A detailed description of the ITC-4 study methods can be found in Thompson et al. ${ }^{14}$ Data on the number and ages of children in the home were available only from the second wave of the survey. As a result, we concentrated our analysis on the cohort who completed both survey waves, the first in around November 2002 and the second on average seven months later (6-10 months). To estimate overall prevalence by country, and changes therein, we also report data on the overall sample at both waves.

\section{Participants}

Study participants included 9046 adult ( 18 years of age and older) smokers (defined as having smoked at least 100 cigarettes lifetime and who currently smoked at least once a month) who agreed to be interviewed as part of the ITC-4 Survey carried out in four English-speaking countries: Canada $(n=2206)$, the United States $(n=2139)$, the United Kingdom $(n=2400)$, and Australia $(n=2301)$. The longitudinal sub-sample numbered 6754 . In addition, we recruited a replenishment sample of 1710 at Wave 2. The original and replenishment samples were broadly representative of their parent populations (but there were some differences between countries; see Thompson et $a l^{14}$ for more detail). Briefly, UK smokers had the lowest number of 18-24 year olds but the greatest number of 55 and over, compared to the other three countries. There were notable differences in household composition: the UK had more who lived alone, and Australia had more who lived in mixed household of smokers and non-smokers. Australia had more households with children under 18 .

The survey field work was conducted using stratified random digit dialling and computer assisted telephone interview (CATI) by two research firms; Roy Morgan Research (Melbourne) for Australia and UK and Environics Research Group (Toronto) for USA and Canada. Stratification was to broad regions to maximise representativeness. It was conducted in English, or in French if desired in the francophone areas of Canada. Strict protocols were developed and implemented to ensure equivalence of methods across the two companies and between the two languages. The study protocol was cleared for ethics by the institutional review boards or research ethics boards in each of the countries. ${ }^{14}$

\section{Measures}

Smoke-free policies in homes for both waves were assessed using the question: "Which of the following best describes smoking in your home?" Response choices included the following: (1) smoking is allowed anywhere in your home;
(2) smoking is never allowed anywhere in your home; and (3) something in between. Respondents were then asked when in a car with non-smokers whether they smoked: normally, never smoked, or something in between. Respondents were also asked about smoking restrictions in bars, restaurants (those who attended them in the last six months), and workplace (those employed outside the home) (see Borland $e t a l^{3}$ ). For analysis we used: (1) smoking is not allowed in any indoor area; (2) other or no restrictions; and (3) non-attenders/not employed. Attitudes to smoking restrictions in hospitals, workplaces, bars and restaurants were assessed using the question: "For each of the following public places, please tell me if you think smoking should be allowed in all indoor areas, in some indoor areas, or not allowed indoors at all?" Respondents were also asked about their daily cigarette consumption and time to first cigarette upon waking from which a behavioural measure of addiction was derived: the heaviness of smoking index $\left(\right.$ HSI $\left.^{15}\right)$, with scores ranging from 0-6. Answers to questions related to number of people aged 18 and older in the household, and the number who smoked, were used to derive a household composition variable, to indicate whether they lived alone, with other smokers or in a mixed household of both smokers and non-smokers. In Wave 2, additional questions relating to whether there were children under 18 living in the household, and if so, the age category they belonged to and number of these children in each category were being asked. Based on their answers, a new variable, youngest child in the household, was derived. Respondents were also asked to report on the number of their five closest friends who smoked; and their agreement with three statements about social denormalisation ${ }^{16}$-for example, "People who are important to you believe that you should not smoke."

Smoking status was determined at the Wave l survey using answers to questions about whether they smoked daily, weekly or monthly and whether they had quit between agreement to participate and conduct of the Wave 1 survey. ${ }^{14}$ At Wave 2, respondents were asked whether they were still smoking or not, and of any quit attempts to arrive at their smoking (smoker, ex-smoker) and quitting (no attempts, tried but failed, and quit) status. In addition, we assessed duration of abstinence, and used quit for a month or more as our criterion of successful quit attempts. Levels of intention to quit were assessed by asking respondents to indicate whether they planned to quit within the next month, within the next six months, beyond six months, or no plans at all.

In addition to the above, demographic variables including age, sex, educational attainment, and income levels were also collected. For income and education we report three level variables that are only roughly comparable across countries due to differences in education systems and problems of equating incomes.

\section{Statistical analysis}

The statistical package SPSS 11.5 was used for all analyses. Percentages reported in tables for country-specific estimates of the levels of variables use weighted data (by age and sex, see Thompson et $a l^{14}$ in this issue) to estimate population prevalence better, but only when we report on the entire Wave 1 sample. Where we rely on the cohort, unweighted data are provided and these figures should not be used as accurate population estimates. All multivariate analyses were first conducted on unweighted data using all potential weighting variables as controls, and then separately on weighted data. For the main regression analyses, we replicated the findings using weighted data, and report only the discrepancy found in the text. Logistic regression was undertaken to assess the predictive power for different independent variables of interest while adjusting for relevant 
demographic and other factors. Covariates controlled for included country of respondent, sex, age, measures of socioeconomic status (SES), and whether the respondent was from an identified minority group. We also tested for interactions with country of respondent in all analyses. For determining predictors of uptake and regression in smokefree homes across the two waves, we employed for our analyses the sub-sample of those in Wave 1 who reported having no total bans and those with total bans, respectively. For analyses of time to first cigarette and cigarettes per day, all statistical analysis was conducted on transformed data, using the square root of cigarettes per day and the natural logarithm of time to first cigarette to normalise the distributions. However, where means are reported, we report them according to the original metric.

\section{RESULTS}

\section{Prevalence of smoke-free home policies}

Table 1 presents the data on smoke-free homes in each country at each wave, along with data on smoking bans in cars. Within the cohort surveyed in both waves, levels of smoke-free homes ranged from $15 \%$ in the UK to $34 \%$ in Australia. This rose in Wave 2 from 19\% in the UK to $43 \%$ in Australia among continuing smokers. Among those who quit smoking between waves, rates were considerably higher at Wave 2. Although not reported in table 1, we also examined reported levels of home restrictions at Wave 2 between continuing smokers recruited at Wave 1 and the replenishment sample of smokers recruited at Wave 2 and found no significant differences between the two groups. For simplicity, we only report data on the continuing cohort. Australia had the highest percentage net change in smoke-free homes between waves with the USA having the lowest. Notably there was more regression away from smoke-free homes in the two North American countries than in either Australia or the UK. Also of note, UK smokers reported the highest levels of bans on smoking in cars. Smokers reporting not smoking when in cars with non-smokers was high and was positively associated with smoke-free homes $(\mathrm{p}<0.001)$.

\section{Associates of smoke-free homes}

We examined the bivariate relationships between levels of restriction in homes in Wave 1 and a number of key sociodemographic variables along with important smokingrelated variables in the same wave and found that there were significant associations for all the variables listed in table 2 . We next examined associations multivariately using logistic regression analyses to identify independent associates of the presence of smoke-free homes in Wave 1; the subsequent uptake of smoke-free homes among those who did not have total bans; and of regression to non-smoke-free homes. For the latter two we did this in two ways: including and excluding those participants who quit between waves. This did not change the pattern of associates to any significant extent. Table 2 reports the data with the quitters excluded. Overall, those quit at Wave 2 were 4.6 (3.5-6.1) times more likely to have implemented smoke-free homes.

We first consider associates of having smoke-free homes at Wave 1. All variables listed in table 2 had bivariate associations (all $\mathrm{p}<0.001$ ). We conducted preliminary logistic regressions including all variables listed with their interactions with country. The only by-country interaction was by age, so this was included in the final model. The 1824 year old smokers from the UK were relatively more likely to have smoke-free homes than those of other age groups as compared to Australia (especially) where the age differences were less pronounced. We also included age and sex by household composition which generally accounted for the main effects of sex and age. This was done as these are characteristics of individuals and the outcome of interest (smoke-free) is a characteristic of the household. Female smokers are more likely to live in smoker-only (adults) homes and younger smokers are more likely to live in mixed households. The strongest predictors of having a smoke-free

Table 1 Overall prevalence and uptake of smoke-free homes and cars by country

\begin{tabular}{|c|c|c|c|c|c|}
\hline \multirow[b]{2}{*}{ Variables } & \multicolumn{4}{|c|}{ Country } & \multirow{2}{*}{$\begin{array}{l}\text { Between country } \\
\text { differences }\end{array}$} \\
\hline & Canada & USA & UK & Australia & \\
\hline \multicolumn{6}{|l|}{$\begin{array}{l}\text { Reported smoking restriction at homes } \\
\text { by smokers in Wave } 1(\%)^{*}\end{array}$} \\
\hline Total ban & 27.3 & 26.4 & 15.3 & 34.1 & $\chi^{2}(6)=344.81, p<0.001$ \\
\hline Partial & 33.6 & 33.6 & 50.3 & 39.3 & \\
\hline None & 39.1 & 40.0 & 34.4 & 26.6 & \\
\hline $\mathrm{n}$ & 2167 & 2085 & 2370 & 2267 & \\
\hline \multirow{2}{*}{\multicolumn{6}{|c|}{$\begin{array}{l}\text { Reported smoking restriction at homes } \\
\text { among Wave } 2 \text { cohort (\%) } \\
\text { Among smokers }\end{array}$}} \\
\hline & & & & & \\
\hline Total ban & 31.5 & 27.9 & 19.0 & 43.1 & $\chi^{2}(6)=311.46, p<0.001$ \\
\hline Partial & 34.1 & 32.0 & 49.5 & 32.6 & \\
\hline None & 34.4 & 40.1 & 31.5 & 24.3 & \\
\hline $\mathrm{n}$ & 1435 & 1192 & 1676 & 1718 & \\
\hline \multicolumn{6}{|l|}{ Among quitters } \\
\hline Total ban & 57.8 & 55.2 & 40.8 & 64.6 & $\chi^{2}(6)=38.24, p<0.001$ \\
\hline Partial & 22.9 & 20.0 & 44.0 & 24.7 & \\
\hline None & 19.3 & 24.8 & 15.2 & 10.8 & \\
\hline $\mathrm{n}$ & 166 & 105 & 184 & 158 & \\
\hline \multicolumn{6}{|l|}{$\begin{array}{l}\text { Between waves among continuing } \\
\text { smokers (\%) }\end{array}$} \\
\hline Implement smoke-free & 8.7 & 5.6 & 5.9 & 7.5 & $\chi^{2}(9)=399.90, p<0.001$ \\
\hline Retain smoke-free & 22.7 & 22.3 & 13.1 & 35.6 & \\
\hline Retain non smoke-free & 62.0 & 66.4 & 80.1 & 55.9 & \\
\hline Regress to smoking & 6.6 & 5.7 & 1.0 & 1.0 & \\
\hline $\mathrm{n}$ & 1433 & 1190 & 1675 & 1717 & \\
\hline Net increase in smoke-free homes (\%) & 2.1 & -0.1 & 4.9 & 6.5 & \\
\hline $\begin{array}{l}\text { Don't smoke in cars with non-smokers } \\
(\% \text { yes })^{*}\end{array}$ & 63.4 & 57.1 & 68.7 & 66.0 & $\chi^{2}(3)=70.16, p<0.001$ \\
\hline n & 2168 & 2084 & 2359 & 2263 & \\
\hline
\end{tabular}


Table 2 Predictors of presence, uptake and regressing of smoke-free homes

\begin{tabular}{|c|c|c|c|}
\hline \multirow[b]{3}{*}{ Predictors } & \multicolumn{3}{|c|}{ Smoke-free homes§ OR (95\% CI) } \\
\hline & \multirow{2}{*}{$\begin{array}{l}\text { W1 Presence } \\
n=6226\end{array}$} & \multirow{2}{*}{$\begin{array}{l}\text { W1-W2 Uptake } † \\
n=4053\end{array}$} & \multirow{2}{*}{$\begin{array}{l}\text { W1-W2 Regressingf } \\
n=1505\end{array}$} \\
\hline & & & \\
\hline \multicolumn{4}{|l|}{ Age (years) } \\
\hline $18-24$ & $2.09(0.97$ to 4.51$)$ & $3.63(1.26 \text { to } 10.45)^{*}$ & $0.32(0.03$ to 3.55$)$ \\
\hline 25 to 39 & $1.78(1.05 \text { to } 3.02)^{*}$ & $1.68(0.80$ to 3.51$)$ & $0.37(0.12$ to 1.12$)$ \\
\hline $40-54$ & $1.18(0.69$ to 1.99$)$ & $1.19(0.56$ to 2.51$)$ & $0.96(0.35$ to 2.65$)$ \\
\hline $55+$ & 1.00 & 1.00 & 1.00 \\
\hline \multicolumn{4}{|l|}{ Sex } \\
\hline Female & $0.83(0.60$ to 1.15$)$ & 1.45 (0.79 to 2.65$)$ & $0.64(0.28$ to 1.45$)$ \\
\hline Male & 1.00 & 1.00 & 1.00 \\
\hline \multicolumn{4}{|l|}{ Education } \\
\hline Low & $1.05(0.86$ to 1.28$)$ & $1.10(0.76$ to 1.60$)$ & $1.86(0.99$ to 3.51$)$ \\
\hline Moderate & $1.03(0.84$ to 1.27$)$ & $1.06(0.72$ to 1.55$)$ & $1.47(0.78$ to 2.78$)$ \\
\hline High & 1.00 & 1.00 & 1.00 \\
\hline \multicolumn{4}{|l|}{ Income } \\
\hline Low & $0.65(0.54 \text { to } 0.79)^{* * *}$ & $0.78(0.56$ to 1.10$)$ & $1.29(0.76$ to 2.18$)$ \\
\hline Moderate & $0.73(0.62 \text { to } 0.85)^{* * *}$ & $0.88(0.67$ to 1.17$)$ & $1.02(0.64$ to 1.63$)$ \\
\hline High & 1.00 & 1.00 & 1.00 \\
\hline Refused & $0.86(0.64$ to 1.14$)$ & 0.58 (0.33 to 1.03$)$ & $1.09(0.51$ to 2.32$)$ \\
\hline \multicolumn{4}{|l|}{ Minority status } \\
\hline Mainstream and non-identified & & & \\
\hline minorities & 1.00 & 1.00 & 1.00 \\
\hline Identified minority & $0.97(0.80$ to 1.18$)$ & $0.85(0.59$ to 1.21$)$ & $1.77(1.07 \text { to } 2.92)^{*}$ \\
\hline Country & & & \\
\hline Canada & 0.84 (0.53 to 1.33$)$ & $1.06(0.76$ to 1.48$)$ & $10.31(5.47 \text { to } 19.43)^{\star * *}$ \\
\hline USA & 1.01 (0.63 to 1.62$)$ & $0.79(0.53$ to 1.17$)$ & 7.56 (3.93 to 14.55$)^{\star \star * *}$ \\
\hline UK & $0.44(0.28 \text { to } 0.69)^{* * *}$ & $0.67(0.47 \text { to } 0.95)^{*}$ & $1.88(0.84$ to 4.21$)$ \\
\hline Australia & 1.00 & 1.00 & 1.00 \\
\hline Household composition (adults) & & & \\
\hline Living alone & 1.00 & 1.00 & 1.00 \\
\hline With other smokers & $1.62(0.93$ to 2.85$)$ & $2.22(0.81$ to 6.13$)$ & $0.14(0.03 \text { to } 0.66)^{*}$ \\
\hline Mixed smokers and non-smokers & $3.50(2.27 \text { to } 5.39)^{\star \star *}$ & $5.16(2.29 \text { to } 11.65)^{\star \star \star *}$ & $0.04(0.01 \text { to } 0.15)^{\star * *}$ \\
\hline Youngest child in household (wave 2) & & & \\
\hline Infant & $2.51(1.73 \text { to } 3.65)^{\star \star \star *}$ & $3.69(2.13 \text { to } 6.37)^{\star \star * *}$ & $0.37(0.10$ to 1.33$)$ \\
\hline Pre-primary & $2.64(2.17 \text { to } 3.21)^{\star * *}$ & $1.43(0.99$ to 2.06$)$ & $0.74(0.44$ to 1.22$)$ \\
\hline Pre-teen & $1.60(1.32 \text { to } 1.94)^{\star \star *}$ & $1.14(0.81$ to 1.60$)$ & $0.56(0.32 \text { to } 0.98)^{*}$ \\
\hline Teen & $1.25(1.01 \text { to } 1.56)^{*}$ & $1.25(0.87$ to 1.80$)$ & $0.74(0.39$ to 1.41$)$ \\
\hline None & 1.00 & 1.00 & 1.00 \\
\hline Smoking status & & & \\
\hline Daily smokers & 1.00 & 1.00 & 1.00 \\
\hline Less than daily & $1.09(0.86$ to 1.38$)$ & $0.71(0.44$ to 1.14$)$ & 1.54 (0.77 to 3.07$)$ \\
\hline Heaviness of smoking index & $0.75(0.71 \text { to } 0.78)^{* * *}$ & $0.78(0.72 \text { to } 0.84)^{* * *}$ & $1.35(1.17 \text { to } 1.56)^{* * *}$ \\
\hline Attitudes to bans elsewhere & $2.17(1.74 \text { to } 2.71)^{* \star *}$ & 1.40 (0.96 to 2.04$)$ & $0.49(0.27 \text { to } 0.86)^{*}$ \\
\hline Reported bans in bars & & & \\
\hline Total bans & $1.10(0.83$ to 1.46$)$ & $1.84(1.17 \text { to } 2.90)^{* *}$ & $0.88(0.37$ to 2.10$)$ \\
\hline Partial/none & 1.00 & 1.00 & 1.00 \\
\hline Not visited venues last 6 months & $1.07(0.91$ to 1.25$)$ & $1.06(0.80$ to 1.41$)$ & $1.18(0.75$ to 1.84$)$ \\
\hline Reported bans in restaurants & & & \\
\hline Total bans & $1.08(0.91$ to 1.27$)$ & $1.13(0.84$ to 1.51$)$ & $0.62(0.38$ to 1.01$)$ \\
\hline Partial/none & 1.00 & 1.00 & 1.00 \\
\hline Not visited venues last 6 months & $0.87(0.67$ to 1.12$)$ & $1.07(0.71$ to 1.63$)$ & $0.70(0.31$ to 1.57$)$ \\
\hline Reported bans in workplace & & & \\
\hline Total bans & $1.13(0.95$ to 1.35$)$ & $1.05(0.78$ to 1.41$)$ & $0.99(0.61$ to 1.63$)$ \\
\hline Partial/none & 1.00 & 1.00 & 1.00 \\
\hline Not employed outside of homes & $1.08(0.89$ to 1.30$)$ & $1.16(0.84$ to 1.60$)$ & $0.97(0.57$ to 1.66$)$ \\
\hline Reported bans in homes at Wave 1 & & & \\
\hline Partial & - & $1.09(0.86$ to 1.40$)$ & - \\
\hline None & - & 1.00 & - \\
\hline Believe ETS causes lung cancer & & & \\
\hline Yes & $1.22(1.04 \text { to } 1.44)^{*}$ & $1.12(0.86$ to 1.47$)$ & $0.69(0.44$ to 1.09$)$ \\
\hline No & 1.00 & 1.00 & 1.00 \\
\hline Social denormalisation index & $1.24(1.11 \text { to } 1.38)^{\star \star *}$ & $0.95(0.79$ to 1.15$)$ & 0.90 (0.65 to 1.23$)$ \\
\hline 5 closest friends who smoke & $0.86(0.82 \text { to } 0.90)^{* * *}$ & 0.96 (0.90 to 1.04$)$ & 0.96 (0.85 to 1.08$)$ \\
\hline Intention to quit & & & \\
\hline Not planning & 1.00 & 1.00 & 1.00 \\
\hline Beyond 6 months & $0.90(0.75$ to 1.07$)$ & $1.47(1.07 \text { to } 2.02)^{*}$ & 1.11 (0.66 to 1.84$)$ \\
\hline Within 6 months & $1.00(0.82$ to 1.22$)$ & $1.43(0.99$ to 2.05$)$ & $1.19(0.68$ to 2.09$)$ \\
\hline Within a month & $1.03(0.81$ to 1.31$)$ & $1.59(1.01 \text { to } 2.50)^{*}$ & $1.32(0.64$ to 2.71$)$ \\
\hline Recent quit attempts (Wave 1) & & & \\
\hline No attempts & 1.00 & - & - \\
\hline Tried but failed & $0.92(0.78$ to 1.08$)$ & - & - \\
\hline Recent quit attempts (Wave 2) & & & \\
\hline No attempts & - & 1.00 & 1.00 \\
\hline Tried but failed & - & $1.49(1.16 \text { to } 1.92)^{* *}$ & $0.77(0.50$ to 1.18$)$ \\
\hline
\end{tabular}


Table 2 Continued

\begin{tabular}{|c|c|c|c|}
\hline \multirow[b]{3}{*}{ Predictors } & \multicolumn{3}{|c|}{ Smoke-free homes§ OR $(95 \% \mathrm{CI})$} \\
\hline & \multirow{2}{*}{$\begin{array}{l}\text { W1 Presence } \\
n=6226\end{array}$} & \multirow{2}{*}{$\begin{array}{l}\text { W1-W2 Uptaket } \\
n=4053\end{array}$} & \multirow{2}{*}{$\begin{array}{l}\text { W1-W2 Regressing } \ddagger \\
n=1505\end{array}$} \\
\hline & & & \\
\hline \multicolumn{4}{|l|}{ Past quit experience } \\
\hline Never & 1.00 & 1.00 & 1.00 \\
\hline 1 week or less & $1.01(0.79$ to 1.29$)$ & $0.96(0.64$ to 1.43$)$ & $0.83(0.45$ to 1.52$)$ \\
\hline$>1$ week to $<6$ months & $1.11(0.91$ to 1.36$)$ & $1.09(0.78$ to 1.54$)$ & $0.94(0.57$ to 1.54$)$ \\
\hline 6 months or more & $1.36(1.12 \text { to } 1.65)^{* *}$ & $1.04(0.73$ to 1.48$)$ & $0.43(0.25 \text { to } 0.74)^{* *}$ \\
\hline Nagelkerke $\mathrm{R}^{2}$ & 0.305 & 0.140 & 0.317 \\
\hline \multicolumn{4}{|c|}{$\begin{array}{l}{ }^{*} \mathrm{p}<0.05 ;{ }^{* *} \mathrm{p}<0.01 ;{ }^{* * *} \mathrm{p}<0.001 \text {. } \\
\text { tLimited to those who did not have smoke-free homes in Wave } 1 \text { and who were smokers on both occasions. } \\
\text { fLimited to those who reported having smoke-free homes at Wave } 1 \text { and who were smokers on both occasions. } \\
\S \text { Significant interaction terms for presence, uptake and regress models are not shown in the table above but are reported in the text. } \\
\mathrm{Cl} \text {, confidence interval, ETS, environmental tobacco smoke; OR, odds ratio. }\end{array}$} \\
\hline
\end{tabular}

home at Wave 1 were having children, especially younger children in the household, having other non-smoking adults in the household, and supporting bans in public venues. There were also positive associations with believing TSP causes cancer, and believing smoke-free was normative (high acceptance of denormalising beliefs about smoking). Characteristics most strongly linked to not having smokefree homes were strength of addiction (HSI), having more smoker friends, being from the UK, and having a low income. Interestingly, only after adding attitudes to smoke-free public places, did reporting presence of total bans in restaurants and workplaces no longer predict having smoke-free homes.

We also explored predictors of implementing smoke-free homes between waves in the continuing smokers, and found the predictors were generally similar (see column 2 in table 2). Here there were no by-country interactions and, again, interactions with household composition generally accounted for the age and sex main effects. Level of intention to quit was a strong predictor with those planning to quit at Wave 1 being more likely to implement smoke-free homes. Similarly those who had made an attempt to quit between waves (and failed) were more likely to implement a smokefree home policy. There were no by-country interactions. It is notable that reporting total bans in bars was associated with increased implementation of smoke-free homes over and above attitudes to smoke-free, which was not significant. This relationship dropped to a trend when the analyses were conducted with weighted data. There was no relationship for bans in restaurants or workplaces.

We also examined factors that might predict those who regressed in smoke-free home policies using the same approach (see column 3 in table 2). Those who were more likely to regress included those identified as being a member of a minority group, being from the USA or Canada, living alone, being highly addicted, and having unfavourable attitudes to smoke-free public places. Those with young children in the household were less likely to regress. As for the predictors of having bans, attitudes mediated the relationship between reported smoke-free public places and regressing, but in these cases it was only reporting smokefree restaurants that was significantly protective before smoke-free attitudes were included. Again, there were no by-country interactions.

Having young children and adult non-smokers in the household are both associated with higher levels of smokefree, and were among the strongest independent predictors. In table 3 we report levels of smoke-free as a function of these variables. However, in all countries most children are

Table 3 Percentage reporting smoke-free homes by country for key household factors

\begin{tabular}{|c|c|c|c|c|c|}
\hline \multirow[b]{2}{*}{ Variables } & \multicolumn{4}{|c|}{ Country } & \multirow[b]{2}{*}{ Between country differences } \\
\hline & Canada & USA & UK & Australia & \\
\hline \multicolumn{6}{|c|}{$\begin{array}{l}\text { Reported smoke-free homes for each type of household adult } \\
\text { composition (\%)* }\end{array}$} \\
\hline Living alone & 16.2 & 18.8 & 8.0 & 21.8 & $\chi^{2}(3)=38.19, p<0.001$ \\
\hline With other smokers & 20.1 & 16.9 & 10.3 & 27.8 & $\chi^{2}(3)=87.66, p<0.001$ \\
\hline Mixed smokers and non-smokers & 39.1 & 39.2 & 23.5 & 44.3 & $\chi^{2}(3)=104.04, p<0.001$ \\
\hline $\mathrm{n}$ & 2194 & 2118 & 2399 & 2301 & \\
\hline \multicolumn{6}{|c|}{$\begin{array}{l}\text { Reported smoke-free homes for each age category of the youngest } \\
\text { child in household (\%) }\end{array}$} \\
\hline Infant & 41.0 & 38.9 & 29.0 & 60.3 & $\chi^{2}(3)=9.49, \mathrm{p}<0.05$ \\
\hline Pre-primary & 48.8 & 51.5 & 26.0 & 52.7 & $\chi^{2}(3)=40.31, p<0.001$ \\
\hline Pre-teen & 38.6 & 29.8 & 16.0 & 42.9 & $\chi^{2}(3)=56.20, p<0.001$ \\
\hline Teen & 30.6 & 32.3 & 12.5 & 36.7 & $\chi^{2}(3)=31.19, p<0.001$ \\
\hline No children & 24.0 & 21.8 & 12.5 & 29.9 & $\chi^{2}(3)=101.55, p<0.001$ \\
\hline $\mathrm{n}$ & 1664 & 1329 & 1863 & 1874 & \\
\hline \multicolumn{6}{|c|}{$\begin{array}{l}\text { Reported smoke-free homes for each type of household and } \\
\text { children combination (\%) }\end{array}$} \\
\hline Mixed household with infant/pre-primary & 59.4 & 56.1 & 39.5 & 62.7 & $\chi^{2}(3)=16.77, p<0.01$ \\
\hline Mixed household with teen/pre-teen & 46.7 & 40.7 & 19.6 & 47.4 & $\chi^{2}(3)=50.85, p<0.001$ \\
\hline Mixed household with no children & 36.4 & 34.3 & 20.0 & 43.2 & $\chi^{2}(3)=63.37, p<0.001$ \\
\hline Smokers household with infant/pre-primary & 32.4 & 41.5 & 12.5 & 45.2 & $\chi^{2}(3)=35.19, p<0.001$ \\
\hline Smokers household with teen/pre-teen & 23.9 & 18.5 & 9.7 & 32.5 & $\chi^{2}(3)=38.06, p<0.001$ \\
\hline Smokers household with no children & 12.7 & 12.3 & 7.2 & 16.0 & $\chi^{2}(3)=22.88, p<0.001$ \\
\hline $\mathrm{n}$ & 1664 & 1329 & 1863 & 1874 & \\
\hline
\end{tabular}

*Percentages are based on weighted data for this part of the table only. 
inadequately protected, with majority protection only likely for younger children in households that also contain nonsmoking adults.

\section{Smoke-free home policies and smoking behaviour}

We explored effects of smoke-free homes on smoking, looking at both smoking patterns and cessation activity. At Wave 1, smoke-free homes were strongly associated with lower consumption and longer time to first cigarette (tables 4 and 5). In the cohort, those implementing bans similarly reduced consumption and increased average time to first cigarette. In addition, we found that those who implemented bans reported a small 1.9 cigarette per day reduction in daily consumption and a large increase of 31.3 minutes in time to first cigarette of the day. As noted above, there was a strong relationship between implementing smoke-free homes and quitting between waves.

We were also interested to test for effects over and above the interactive effect associated with implementing bans in the process of quitting, so we dropped those who changed their smoke-free policy between waves from the analysis. We found (table 6) a strong bivariate relationship between the presence of smoke-free home policies at Wave 1 on both making a quit attempt between waves and, among those who tried, the short-term success of that attempt (quit for a month or more and still quit versus relapsed within a month). These significant effects remained when we included controls for demographic characteristics, household smoker composition, social normative variables, and the reported presence of bans in various public venues. The effects for making a quit attempt disappeared when proximal predictors of quitting were included, ${ }^{17}$ and subsidiary analyses revealed that the mediators included HSI (an index of addiction), daily versus non-daily smoking, functional value of smoking, and intentions to quit at Wave 1. For quit success, when the proximal quit predictors were added, the direct relationship with smoke-free homes remained significant, those with a smoke-free home being twice as likely to be quit for at least a month (odds ratio 2.07, 95\% confidence interval 1.20 to $3.56 ; \mathrm{p}=0.009$ ). There were no effects for partially smoke-free homes.

Finally, we tested for an interactive effect of quit intentions on the effects of smoke-free. For neither making attempts nor remaining quit for at least a month was there a significant interaction, when comparing those in preparation with those less advanced ( $\mathrm{p}$ values were all greater than 0.6 ).

\section{DISCUSSION}

This study shows increased levels of smoke-free homes in three of the four countries studied over a period of around seven months. There was no net increase in the USA. Australia has notably higher rates of smoke-free homes which increased slightly over the period of this study, due to a combination of high rates of implementation and low rates of regression. These are not simple country effects, as there is regional variability. Analyses (not reported here) of the USA data by state indicates that levels of smoke-free homes in California are higher than in Australia, while most other states have far lower levels. It is tempting to equate levels of smoke-free homes with the length and strength of tobacco control programmes. The UK having the lowest levels is consistent with it being last of the four countries studied to take tobacco seriously, and Australia and Canada have generally led most of the USA, with the exception of California, and some smaller US states, which have spent more per capita, over the last decade. ${ }^{18}$ Certainly, the pattern is consistent with a long term role of campaigns and programmes; however, we cannot be sure as this study has too short a time window to understand a process which has been ongoing for 20 years or more.

Caution is required in inferring causation from any of these results. We believe that where the effects are found longitudinally and can be shown to be mediated as theorised, then inference of causation is warranted, but it remains an

\begin{tabular}{|c|c|c|c|c|c|c|}
\hline & \multicolumn{2}{|c|}{ Cigs per day } & \multicolumn{2}{|c|}{ Time to first cig (mins) } & \multirow{3}{*}{$\begin{array}{l}\% \text { quit } \\
\text { attempt }^{\star * *}\end{array}$} & \multirow{3}{*}{$\begin{array}{l}\% \text { successful } \\
\text { (among } \\
\text { attempters) }\end{array}$} \\
\hline & Raw & Transformed & Raw & Transformed & & \\
\hline & $M^{* \star *}$ & $M( \pm S D)^{\star \star \star}$ & $M^{* \star *}$ & $M( \pm S D)^{\star \star *}$ & & \\
\hline \multicolumn{7}{|l|}{$\begin{array}{l}\text { Home smoke-free } \\
\text { conditions (Wave 1) }\end{array}$} \\
\hline Total $(n=1827)$ & 13.6 & $3.4(1.3)$ & 110.7 & $3.8(1.4)$ & 41.1 & 29.6 \\
\hline Partial $(n=2671)$ & 16.5 & $3.9(1.2)$ & 77.4 & $3.3(1.4)$ & 37.1 & 25.8 \\
\hline None $(n=2166)$ & 21.1 & $4.5(2.4)$ & 40.8 & $2.7(1.4)$ & 31.4 & 18.8 \\
\hline
\end{tabular}

Table 5 Consumption patterns by home smoke-free conditions (Wave 1 to Wave 2)

\begin{tabular}{|c|c|c|c|c|c|c|}
\hline & \multicolumn{2}{|c|}{ Change in cigs per day } & \multicolumn{2}{|c|}{ Change in time to first cig } & \multirow{3}{*}{$\begin{array}{c}\% \text { quit } \\
\text { attempt }^{\star \star *}\end{array}$} & \multirow{3}{*}{$\begin{array}{l}\% \text { successful } \\
\text { (among } \\
\text { attempters) }\end{array}$} \\
\hline & Raw & Transformed & Raw & Transformed & & \\
\hline & M & $M( \pm S D)^{* *}$ & $M^{* * *}$ & $M( \pm S D)^{* *}$ & & \\
\hline \multicolumn{7}{|c|}{$\begin{array}{l}\text { Change in home smoke-free (SF) conditions } \\
\text { (W1-W2) }\end{array}$} \\
\hline Maintain SF $(n=1379)$ & 1.2 & $0.1(0.8)$ & -5.4 & $-0.1(0.9)$ & 41.9 & 29.7 \\
\hline Implement SF $(n=398)$ & 1.9 & $0.3(0.9)$ & -31.3 & $-0.3(1.1)$ & 55.6 & 39.1 \\
\hline Regress from SF $(n=191)$ & 0.6 & $0.1(0.9)$ & -7.3 & $0.0(1.3)$ & 34.7 & 28.0 \\
\hline Remain non-SF $(n=3918)$ & 0.9 & $0.1(0.9)$ & -9.5 & $-0.1(0.9)$ & 31.5 & 18.8 \\
\hline
\end{tabular}




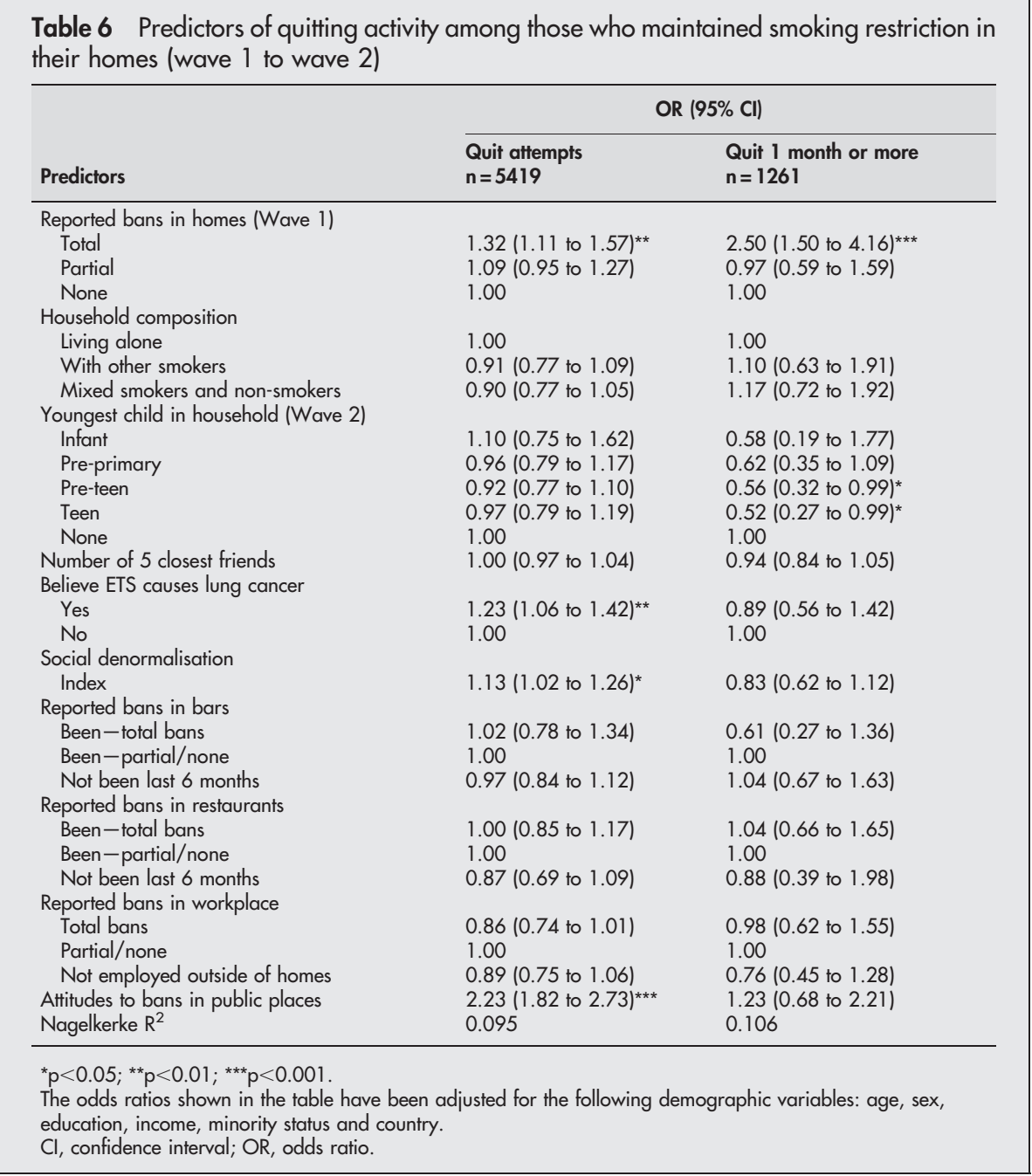

inference not a definitive demonstration. Consistent with previous research findings ${ }^{579}$ restrictions are more common when smokers live with other non-smoking adults and where there are children present. Our findings extend this to show that these factors are also prospective predictors of the implementation of smoke-free homes. This was especially so for the presence of infants. It is plausible that having a baby acts as a major stimulus for implementing bans as most parents are concerned to maximise the health of their babies. Having children is also a major factor protecting against regression from smoke-free, again plausibly causative as pressure from children does influence parental behaviour, and children are often strongly anti-smoking. The expectations of important others such as family members and close friends are also clearly an influential factor associated with smoke-free homes.

Currently too many smokers continue to allow their families to be exposed to their smoke, and more is needed to encourage and provide the conditions under which more homes can be made smoke-free.

It is reassuring to find that the lower levels of implementation of smoke-free among those of lower SES are mediated by smoking-related variables (higher levels of addiction and a more pro-smoking social environment) rather than more fundamental social forces, suggesting that it can be tackled through tobacco control policies. Lower SES smokers appear no less motivated to be smoke-free, but unless the extra barriers they face are dealt with, their families will remain underprotected. We need to work, in parallel with other attempts to denormalise smoking, to provide extra support to help those less advantaged smokers who need to at least have the benefits of smoke-free homes. This needs to include provision of cessation services as in some cases smokers see quitting as an easier option than implementing smoke-free in environments where smoking outdoors is difficult. ${ }^{19}$

Understanding patterns of uptake of smoke-free homes is important for providing a context in which to develop interventions to encourage more smoke-free homes. All homes that contain non-smokers, either children or adult, should be smoke-free to protect the non-smokers. Homes with children should also be smoke-free to provide a good role model to children. Interventions could usefully exploit times when spontaneous change is most likely, like having children (there are other good reasons to act at this time), but they should not restrict themselves to these situations, as this will leave those without propitious factors lingering in smoke-filled homes for far longer than they should.

This study provides more evidence that smoke-free public places facilitate rather than inhibit the introduction of smoke-free homes. It replicates the cross-sectional association observed between smoke-free public places and having smoke-free homes. ${ }^{58}$ We found that attitudes to public-place policies were more strongly correlated with smoke-free homes than reports of having smoke-free public places. However, for newly implemented smoke-free homes we found that reporting smoke-free bars was directly predictive, and attitudes were not. Given the small magnitude of this effect and its instability, we would like to see it replicated 
before we were confident in attributing a specific role to smoke-free bars. That said, the finding of a direct effect of smoke-free bars on implementation, and no effect of attitudes to smoke-free public places in this case, raises the possibility that the relationship with attitudes is not causal for implementing smoke-free homes, rather that it reflects a realignment of attitudes post-introduction of smoke-free homes. If this were so, it would suggest that smoke-free public places are the driving factor. As to why we would find the relationship for smoke-free bars, but not other smokefree places, there is no definitive answer. Bars may constitute a more important social venue for many, and/or one where smoking is seen as more integral to the core reason for being there; thus it may be that different mechanisms are involved with bars as compared to workplaces and restaurants. Further research is needed to untangle the relationships. Overall, our findings, along with the positive association between smokefree homes and not smoking in cars when non-smokers are present, provide support for the social diffusion theory and effectively disconfirm the last refuge model that some opponents of smoke-free public places have proposed.

The finding that quitters and those in the process of quitting are more likely to adopt smoke-free homes suggests that smoke-free homes may often be implemented in the context of quit attempts. The finding that having smoke-free homes both facilitates making quit attempts and reduces relapse, reinforces the value of encouraging smokers to adopt smoke-free policies for their homes, as it can both protect their families from TSP and help them quit permanently.

Our findings replicate and extend findings on the relationship between smoke-free homes and cessation. There is now consistent evidence ${ }^{12} 13$ that smoke-free homes encourage cessation. Our findings suggest separate effects of the implementation of smoke-free on the presence of smokefree. Having smoke-free homes or implementing them creates or interacts with other influences on cessation to increase the probability of attempting to quit. Smoke-free homes also appear to have an independent role in helping quitters avoid relapse. Unlike the findings of Pizacani et al, ${ }^{13}$ we found that the positive effects of smoke-free were independent of stage of change. Our results considerably strengthen the case for smoke-free homes playing a causal role in the encouragement of and maintenance of smoking cessation.

This study has a number of strengths. The finding that the factors related to having smoke-free homes and their effects on behaviour were remarkably similar across the four countries of this study suggests considerable generalisability of the findings. That said, caution should be exercised in generalising beyond the four countries studied since all are affluent, primarily English speaking cultures.

The findings of this study only relate to homes with smokers. Introduction of smoke-free homes in households where nobody smokes is quite a different issue. Some do implement formal bans, but others, especially those for whom it is never an issue, may have no household policy, yet maintain a completely smoke-free environment. It is only where there are smokers that the need for a policy is clear. Our study focuses on the area where the most health protection can occur-homes with smokers in them.

A limitation of this study is a reliance on self-reported measures of a smoking ban in homes. However, a review by Hovell et $a l^{20}$ suggests that self-report of TSP exposure of children is moderately related to either environmental or biological measures of TSP exposure and has sufficient validity to be employed in research. Nevertheless, some caution should be exercised in interpreting the results.

Another limitation is that smoke-free homes are a household event and many of our predictors were characteristics of

\section{What this paper adds}

This paper shows that the determinants of smoke-free homes and their effects on quitting are remarkably consistent across four affluent western countries, suggesting high generalisability of their effects. It confirms that the implementation of smoke-free environments in homes inhabited by smokers is slightly facilitated by the presence of smoke-free public places, especially recreational venues, and is definitely not inhibited by such public places policies. This means that policymakers can be reassured that smoke-free public places are unlikely to push smoking into homes, potentially increasing exposures of family members of smokers. In addition, this paper confirms and extends our understanding of the role of smoke-free homes in facilitating quitting activity. Smoke-free homes lead to a reduction in behaviourally assessed dependence, and increases in interest in quitting, and also, independent of other variables, contributes to maintenance of cessation once quit. Smokers are increasingly making (or allowing) their homes to be smoke-free, and in doing so, they are protecting their families and helping themselves gain greater control over their dependence, thus facilitating cessation attempts.

one family member. We might expect better prediction if we could have included more information about the characteristics of other family members, as some of these variables we did include were important predictors. That said, it seems unlikely that any of the factors we identified as important would not remain important.

In conclusion, smoke-free homes containing smokers are becoming more prevalent in the countries studied and having a smoke-free home can help smokers quit. Apart from the need to protect non-smokers, these are good reasons for all smokers who either have non-smokers in their homes and/or who are interested in quitting (most are) to consider making their homes smoke-free. Governments and health authorities should be actively promoting such strategies through public education with carefully pre-tested messages designed to appeal to the sensitivities of their target audiences. That said, moves by government to make public places smoke-free, perhaps especially venues used for socialising, may be their most important contribution to encouraging householders to extend these policies into their homes. Smokers should be encouraged to embrace smoke-free homes as a means of gaining greater control over their smoking as well as to protect their families.

\section{ACKNOWLEDGEMENTS}

This research was supported by grants R01 CA 100362 and P50 CAl11236 (Roswell Park Transdisciplinary Tobacco Use Research Center) from the National Cancer Institute of the United States, Robert Wood Johnson Foundation (045734), Canadian Institutes of Health Research (57897), National Health and Medical Research Council of Australia (265903), Cancer Research UK (C312/A3726), Canadian Tobacco Control Research Initiative (014578); Centre for Behavioural Research and Program Evaluation, National Cancer Institute of Canada/Canadian Cancer Society. Role of the funding sources: The funding sources had no role in the study design, in the collection, analysis, and interpretation of data, in the writing of the report, and in the decision to submit the paper for publication. We would also like to acknowledge the other members of the ITC-4 team.

\section{Authors' affiliations}

R Borland, H-H Yong, The Cancer Council Victoria, Australia

K M Cummings, A Hyland, Roswell Park Cancer Institute, Buffalo, New York, USA 
S Anderson, Centre for Tobacco Control Research, University of Stirling/ Open University, Stirling, UK

G T Fong, University of Waterloo, Waterloo, Ontario, Canada

The authors have no conflicts of interest

The paper was conceived by Ron Borland who did the bulk of the writing assisted by Hua Yong, especially with respect to the results. The other coauthors, Hyland, Cummings, Anderson and Fong, all read and commented on drafts and added content.

Ethics approval: The study protocol was cleared for ethics by the Institutional Review Boards or Research Ethics Boards in each of the countries: the University of Waterloo (Canada), Roswell Park Cancer Institute (USA), the University of Illinois-Chicago (USA), the University of Strathclyde (UK), and the Cancer Council Victoria (Australia).

\section{REFERENCES}

1 Gerlach KK, Shopland DR, Hartman AM, et al. Workplace smoking policies in the United States: results from a national survey of more than 100,000 workers. Tob Control 1997:6:199-206.

2 Borland R, Davey C. Impact of smoke-free bans and restrictions. In: Boyle P, Gray N, Henningfield J, Seffrin J, Zatonski W, eds. Tobacco-science, policy and public health. Oxford: Oxford University Press, 2004:708-32.

3 Borland R, Yong H-H, Siahpush M, et al. Support for and reported compliance with smoke-free restaurants and bars by smokers in four countries: findings from the International Tobacco Control (ITC) Four Country Survey. Tob Control 2006; 15(suppl III):iii34-41.

4 Ashley MJ, Cohen J, Ferrence R, et al. Smoking in the home: changing attitudes and current practices. Am J Public Health 1998:88:797-800.

5 Borland R, Mullins R, Trotter $L$, et al. Trends in environmental tobacco smoke restrictions in the home. Tob Control 1999;8:266-71.

6 Soliman S, Pollack HA, Warner KE. Decrease in the prevalence of environmental tobacco smoke exposure in the home during the 1990s in families with children. Am J Public Health 2004;94:314-20.

7 Gilpin E, White $M$, Farkas A, et al. Home smoking restrictions: which smokers have them and how they are associated with smoking behaviour. Nicotine Tob Res 1999;1:153-62.
8 Merom D, Rissel C. Factors associated with smoke-free homes in NSW: results from the 1998 NSW Health Survey. Austr N Z J Public Health $2001 ; 25: 339-45$.

9 Norman G, Ribisi K, Howard-Pitney B, et al. Smoking bans in the home and car: do those who really need them have them. Prev Med 1999;29:581-9.

10 Pizacani BA, Martin DP, Stark MJ, et al. Household smoking bans: which households have them and do they work? Prev Med 2003;36:99-107.

11 Biener L, Cullen D, Di ZX, et al. Household smoking restrictions and adolescents' exposure to environmental tobacco smoke. Prev Med 1997;26:358-63.

12 Farkas AJ, Gilpin EA, Distefan JM, et al. The effects of household and workplace smoking restrictions on quitting behaviours. Tob Control 1999;8:261-5.

13 Pizacani BA, Martin DP, Stark MJ, et al. A prospective study of household smoking bans and subsequent cessation related behaviour: the role of stage of change. Tob Control 2004;13:23-8.

14 Thompson ME, Fong GT, Hammond D, et al. Methods of the International Tobacco Control (ITC) Four Country Survey. Tob Control 2006; 15(suppl III):iii12-18.

15 Heatherton TF, Kozlowski L, Frecker RC, et al. Measuring the heaviness of smoking: using self-reported time to the first cigarette of the day and number of cigarettes smoked per day. Br J Addiction 1989;84:791-9.

16 Hammond D, Fong GT, Elton-Marshall T, et al. Tobacco denormalization and cessation behaviour among smokers from four countries: findings from the International Tobacco Control (ITC) Four Country Survey. Am J Prev Med (in press).

17 Hyland A, Borland R, Li Q, et al. Individual-level predictors of cessation behaviours among participants in the International Tobacco Control (ITC) Four Country Survey. Tob Control 2006; 15(suppl III):iii83-94

18 Farrelly MC, Pechacek TF, Chaloupka FJ. The impact of tobacco conto program expenditures on aggregate cigarette sales: 1981-2000. [Erratum in J Health Econ2004;23:419] J Health Econ 2003;22:843-59.

19 Hill L, Farquarson K, Borland R. Blowing smoke: strategies smokers use to protect non-smokers from environmental tobacco smoke in the home. Health Promotion Journal of Australia 2003;14:196-201.

20 Hovell MF, Zakarian JM, Wahlgren DR, et al. Reported measures of environmental tobacco smoke exposure: trials and tribulations. Tob Control 2000;9(suppl III):iii22-8. 